\title{
Transfer Assessment of Carbendazim Residues from Rape Flowers to Apicultural Products
}

\author{
Ying-Hong Li, ${ }^{1}$ Bei-Lei Zhou, ${ }^{2}$ Ming-Rong Qian, ${ }^{2}$ Qiang Wang, ${ }^{2}$ and Hu Zhang ${ }^{2}$ \\ ${ }^{1}$ Zhejiang Institute for Food and Drug Control, Hangzhou 310052, China \\ ${ }^{2}$ Institute of Quality and Standard for Agricultural Products, Zhejiang Academy of Agricultural Sciences, Hangzhou 310021, China \\ Correspondence should be addressed to Hu Zhang; zhanghu@mail.zaas.ac.cn
}

Received 22 October 2016; Accepted 4 January 2017; Published 26 January 2017

Academic Editor: Miguel de la Guardia

Copyright (c) 2017 Ying-Hong Li et al. This is an open access article distributed under the Creative Commons Attribution License, which permits unrestricted use, distribution, and reproduction in any medium, provided the original work is properly cited.

\begin{abstract}
Carbendazim is usually used to control the Sclerotinia sclerotiorum of rapes during the flowering period. This paper presents a study on transfer assessment of carbendazim residues from rape flowers to apicultural products. In the field trials, the rapes were sprayed with carbendazim on standard dosage. Bees produced apicultural products (bee pollen, honey, and royal jelly) from sprayed rapes. Apicultural products were collected on a regular basis. Carbendazim residues were extracted from bee pollen, honey, and royal jelly, respectively. HPLC/ESI-MS/MS method was developed and partially validated to identify and quantify carbendazim residues. The limits of quantification in pollen, honey, and royal jelly were $0.01 \mathrm{mg} / \mathrm{kg}$. Mathematical curve fitting was carried out on the basis of transfer assessment of carbendazim residues from rape flowers to apicultural products. The respective carbendazim residues were $1.10 \pm 0.03 \mathrm{mg} / \mathrm{kg}$ in pollen on $18 \mathrm{th}$ day, $0.032 \pm 0.001 \mathrm{mg} / \mathrm{kg}$ in honey on 24 th day, and $0.077 \pm 0.002 \mathrm{mg} / \mathrm{kg}$ in royal jelly on $22 \mathrm{nd}$ day. Transfer assessment and mathematical curve fitting of carbendazim residues from rape flowers to apicultural products show carbendazim diminished over spraying time. The gap of carbendazim residues between pollen and honey is decreased with time. The carbendazim residues in pollen are 10 times higher than that of honey and jelly.
\end{abstract}

\section{Introduction}

Pesticides have played an important role in controlling, seducing, and preventing pests and, hence, indirectly increasing food production. The use of pesticides in agricultural activities has adverse effects towards human, which can be detrimental to food safety. Many studies have focused on the direct pollution on food from residual pesticides. Moreover, some reports suggested that pesticide residues could transfer to animal food through animal feeds [1-3]. But little research has been performed on pesticide residues in apicultural matrixes from field samples.

Apicultural products such as bee pollen, honey, and royal jelly are popular agricultural products in the world. Apicultural products have been found to exhibit interesting bioactivities, such as antimicrobial, anti-inflammatory, and antioxidant activities [4]. In China, annual output and exports of apicultural products are always ranked first in the world. Nectar plants are the source and basis for bees to collect nectar and pollen. Rapes are the main nectar plants for bees in terms of sown area in China. Rapes are widely cultivated in the Yangtze River Basin of China due to wide application and high economic value.

However, rapes easily suffered from diseases damage during whole growth period, which are significant factors threatening the rapeseed yield [5]. In agricultural practice for rape fields, fungicides as certain category of pesticides are always used for protecting rapes [6]. Carbendazim is one of the benzimidazole fungicides, which has good control effects against Sclerotinia sclerotiorum of rapes in the rape flowering. However, rape flowers are polluted due to spraying the pesticides during rape flowering period and will lead to pesticide residues in apicultural products. For example, pollen of oilseed rape was heavily contaminated with a broad range of pesticides, as was the pollen of wild flowers growing nearby. Consequently, pollen collected by both bee species also contained a wide range of pesticides, notably including the fungicides carbendazim, boscalid, flusilazole, metconazole, tebuconazole, trifloxystrobin, neonicotinoids, thiamethoxam, thiacloprid, and imidacloprid [7]. Therefore, 
level of pesticide residues in apicultural products is closely related to the pollution degree of rape flowers. While the inconvenient truth is that exports of Chinese apicultural products are blocked by technical barriers to trade due to the abuse of chemical pesticides [8], European Union and Japan have strengthened controls on pesticide residue in apicultural products. Therefore, it has great significance to detect pesticide residues in apicultural products. Many researches are carried out to determine the pesticide residues in final apicultural products. LC-MS/MS and GC-MS/MS for the determination of 200 pesticides and pesticide metabolites in honeybee samples have been developed and validated [9]. Especially to deserve to be mentioned, there are studies on pesticide residue transfer rates or percent, such as transfer assessment of fipronil residues from feed to cow milk [1] and pesticide residue transfer rates (percent) from dried tea leaves to brewed tea $[10,11]$. However, the domestic researches on pesticide accumulation from nectar plants to apicultural products are rare $[12,13]$. Honey bee (Apis mellifera carnica) colonies were placed in two apple orchards treated with the insecticides diazinon and thiacloprid and the fungicide difenoconazole in accordance with a Protection Treatment Plan in the spring of 2007, and pollen and bee bread were collected from combs inside the hives to determine the residues of pesticides [14]. Concentration levels of 30 pesticide residues were measured in honey samples collected from apiaries in northern part of Poland (Pomerania) using method based on the QuEChERS Extraction followed by HPLC/ESI-MS/MS, and 29\% of the samples were found positive for at least some of the target compounds [15]. It shows the necessity and urgency to carry out relevant research.

In the current study, the field trials were designed to spray carbendazim over rapes during the flowering period. Apicultural products (bee pollen, honey, and royal jelly) obtained by bees from sprayed rapes were collected on a regular basis. The transfer assessment of carbendazim residues from rape flowers to apicultural products was figured out by HPLC/ESI-MS/MS method. Mathematical analysis for curve fitting of transferring pattern was identified by computer associated calculation. This study aimed to improve security level of apicultural products and provide basis data to establish maximum residue limits (MRL) and safe intervals of corresponding fungicides.

\section{Materials and Methods}

2.1. Materials and Chemicals. Methanol and acetonitrile with LC-MS grade were purchased from Merck (Darmstadt, Germany). Acetic acid ( $\geq 99.7 \%$ purity) was obtained from Sigma-Aldrich (St. Louis, USA). The Oasis HLB cartridges $(6 \mathrm{cc} / 150 \mathrm{mg}, 30 \mu \mathrm{m})$ were provided by Waters Ltd. (USA). QuEChERS Extraction kits (1.5 g anhydrous sodium acetate and $6 \mathrm{~g}$ anhydrous $\mathrm{MgSO}_{4}, 50 \mathrm{~mL}$ centrifuge tubes) and QuEChERS Clean-Up kits (150 mg anhydrous $\mathrm{MgSO}_{4}, 50 \mathrm{mg}$ Primary and Secondary Amine (PSA), and $50 \mathrm{mg} \mathrm{C}_{18}, 2 \mathrm{~mL}$ centrifuge tubes) were purchased from Phenomenex Inc. (USA). Water $(18.2 \mathrm{M} \Omega \cdot \mathrm{Cm})$ used for reagent and sample preparation was from a Barnstead Nanopure system (Thermo Scientific, USA). All other chemicals were of analytical reagent grade. Analytical standards of carbendazim (purity 99.0\%) and the internal standard carbendazim-D3 (purity 99.0\%) were purchased from Dr. Ehrenstorfer GmbH (Augsburg, Germany). Stock standards (approximately $100 \mathrm{mg} / \mathrm{L}$ ) of the individual compounds were prepared by dissolving the reference compounds in methanol. Working standards at lower concentrations were prepared by serial dilution of the stock standards by blank matrixes.

2.2. Field Trials. Field experiments were designed scientifically, in accordance with the field trial standard of pesticide residue. The field experiments were conducted during March-April 2014. The trials were conducted in experimental fields located in Zhejiang academy of agricultural sciences (Hangzhou, China). Zheshuang 72 double low Brassica, as a typical Brassica napus and breed by Zhejiang academy of agricultural sciences, was registered and released by national variety certification in 2001. Zheshuang 72 was chosen as the experiment rape. During the experiment, total 13816 plants of Zheshuang 72 were transplanted averagely to four GP 622 single-span greenhouses with the organic farming system. Each single-span greenhouse was constructed by high-strength stainless steel wire mesh. The greenhouse was about $288 \mathrm{~m}^{2}, 48$ meters in length, 6 meters in width, and 3.1 meters in height. Four GP 622 single-span greenhouses were numbered from $\mathrm{P}_{1}$ to $\mathrm{P}_{4}$. $\mathrm{P}_{1}$ greenhouse was set as blank control plot. $\mathrm{P}_{2}$ to $\mathrm{P}_{4}$ greenhouses were set as paralleled experimental plots. All rapes planted in $\mathrm{P}_{2}$ to $\mathrm{P}_{4}$ greenhouses were treated with 50\% carbendazim WP (Pianjing plant protection Technology Co., Ltd, Suzhou, China) at flowering period by Jecto HD 400 hand-operated knapsack sprayer. The spraying concentration of pesticide was $432 \mathrm{mg} / \mathrm{kg}$ as recommended max-concentration (1500 g.a.i./ha). After the pesticide spraying, 4 beehives about 5000 bees in each hive were placed in $\mathrm{P}_{1}$ to $\mathrm{P}_{4}$ greenhouses, respectively. Apicultural products (bee pollen, honey, and royal jelly) from $\mathrm{P}_{1}$ to $\mathrm{P}_{4}$ green houses were collected on a regular basis as shown in Table 1. All apicultural products were carefully labeled and immediately transported and stored in the laboratory at $-20^{\circ} \mathrm{C}$ until analyzed.

\subsection{Sample Preparation and Extraction Procedure}

2.3.1. Bee Pollens. Sample extraction and clean-up procedures followed the buffered QuEChERS (Quick, Easy, Cheap, Effective, Rugged, and Safe) method [16-18]. The homogenized pollen $(3 \mathrm{~g})$ was weighted into a $50 \mathrm{~mL}$ centrifuge tube, followed by addition of $0.3 \mathrm{~mL} 1.0 \mathrm{mg} / \mathrm{L}$ carbendazim-D3 internal standard working solution. $12 \mathrm{~mL}$ purified water and $15 \mathrm{~mL}$ acetonitrile with $1 \%$ acetic acid were added after staying in static state for $20 \mathrm{~min}$. Then the tube was shaken vigorously for $1 \mathrm{~min}$ using a vortex mixer. QuEChERS Extraction kits with $6 \mathrm{~g}$ anhydrous $\mathrm{MgSO}_{4}$ and $1.5 \mathrm{~g}$ anhydrous sodium acetate were added. Then the tube was shaken vigorously for $5 \mathrm{~min}$ using a vortex mixer and centrifuged at 5,000 rpm for $5 \mathrm{~min} .1 \mathrm{~mL}$ of the acetonitrile extracts (upper layer) was transferred into a $2 \mathrm{~mL}$ centrifuge tube named as QuEChERS Clean-Up kits with $50 \mathrm{mg}$ PSA, $50 \mathrm{mg} \mathrm{C} \mathrm{C}_{18}$, and $150 \mathrm{mg}$ anhydrous $\mathrm{MgSO}_{4}$. After shaking and centrifugation, $0.5 \mathrm{~mL}$ 
TABLE 1: Sampling table of field trials.

\begin{tabular}{|c|c|c|c|c|c|}
\hline \multirow[t]{2}{*}{ Sampling date } & \multirow[t]{2}{*}{ Weather } & \multirow[t]{2}{*}{$\begin{array}{c}\text { Time after application } \\
\text { (days) }\end{array}$} & \multicolumn{3}{|c|}{$\begin{array}{c}\text { Greenhouses } \\
\mathrm{P}_{1} \text { (blank), } \mathrm{P}_{2} \sim \mathrm{P}_{4} \text { (test) }\end{array}$} \\
\hline & & & Pollen & Honey & Jelly \\
\hline 23 March & Sunny & 0 & & & \\
\hline 24 March & Cloudy & 1 & $\checkmark$ & $\checkmark$ & \\
\hline 26 March & Overcast & 3 & $\checkmark$ & & $\checkmark$ \\
\hline 27 March & Cloudy & 4 & $\checkmark$ & $\checkmark$ & \\
\hline 29 March & Moderate rain & 6 & & $\checkmark$ & $\checkmark$ \\
\hline 1 April & Cloudy & 9 & & $\checkmark$ & $\checkmark$ \\
\hline 2 April & Overcast & 10 & $\checkmark$ & & \\
\hline 4 April & Cloudy & 12 & $\checkmark$ & & $\checkmark$ \\
\hline 5 April & Sunny & 13 & $\checkmark$ & $\checkmark$ & \\
\hline 7 April & $\begin{array}{l}\text { Rain } \\
\text { Shower }\end{array}$ & 15 & & & $\checkmark$ \\
\hline 9 April & Cloudy & 17 & & $\checkmark$ & \\
\hline 10 April & Sunny & 18 & $\checkmark$ & $\checkmark$ & $\checkmark$ \\
\hline 14 April & Sunny & 22 & & & $\checkmark$ \\
\hline 16 April & $\begin{array}{l}\text { Rain } \\
\text { Shower }\end{array}$ & 24 & & $\checkmark$ & \\
\hline
\end{tabular}

of the upper layer was transferred into a $2 \mathrm{~mL}$ centrifuge tube containing $0.5 \mathrm{~mL}$ purified water. The vial was capped and then vortexed for $30 \mathrm{~s}$, and the final solution was filtered through a $0.22 \mu \mathrm{m}$ filter for HPLC/ESI-MS/MS analysis.

2.3.2. Bee Honey. The homogenized honey ( $5 \mathrm{~g})$ was weighted into a $50 \mathrm{~mL}$ centrifuge tube, followed by addition of $0.5 \mathrm{~mL}$ $1.0 \mathrm{mg} / \mathrm{L}$ carbendazim-D3 internal standard working solution; $25 \mathrm{~mL}$ purified water was added after staying in static state for $20 \mathrm{~min}$. Then the tube was shaken vigorously for $1 \mathrm{~min}$ using a vortex mixer and centrifuged at $5,000 \mathrm{rpm}$ for $5 \mathrm{~min}$. The upper layer solution was transferred at $5 \mathrm{~mL} / \mathrm{min}$ into the Oasis HLB cartridge $(6 \mathrm{cc} / 150 \mathrm{mg}, 30 \mu \mathrm{m})$, which was conditioned previously with $5 \mathrm{~mL}$ of methanol and $5 \mathrm{~mL}$ of water. The column was then washed with $15 \mathrm{~mL}$ of water for cleaning up. $10 \mathrm{~mL}$ methanol was used for eluting and the elution liquid was collected. The elution liquid was immersed in a gentle stream of nitrogen and concentrated to dryness. Finally $5 \mathrm{~mL}$ of $50 \%$ methanol solution was added to restore the volume. The final solution was filtered by $0.22-\mu \mathrm{m}$ membrane and then determined by HPLC/ESI-MS/MS.

2.3.3. Bee Jelly. The homogenized jelly $(2 \mathrm{~g})$ was weighted into a $50 \mathrm{~mL}$ centrifuge tube, followed by addition of $0.1 \mathrm{~mL}$ $1.0 \mathrm{mg} / \mathrm{L}$ carbendazim-D3 internal standard working solution; $10 \mathrm{~mL}$ purified water was added after staying in static state for $20 \mathrm{~min}$. Then the tube was shaken vigorously for $1 \mathrm{~min}$ using a vortex mixer and then volume to $20 \mathrm{~mL}$ by addition of methanol. Then the tube was shaken vigorously for $1 \mathrm{~min}$ again and centrifuged at 5,000 rpm for $5 \mathrm{~min}$. $10 \mathrm{~mL}$ of upper layer solution was diluted by $25 \mathrm{~mL}$ water and transferred at $5 \mathrm{~mL} / \mathrm{min}$ into the Oasis HLB cartridge $(6 \mathrm{cc} / 150 \mathrm{mg}, 30 \mu \mathrm{m})$ after mixing, which was conditioned previously with $5 \mathrm{~mL}$ of methanol and $5 \mathrm{~mL}$ of water. The column was then washed with $15 \mathrm{~mL}$ of water for cleaning up. $10 \mathrm{~mL}$ methanol was used for eluting and the elution liquid was collected. The elution liquid was immersed in a gentle stream of nitrogen and concentrated to dryness. Finally $5 \mathrm{~mL}$ of $50 \%$ methanol solution was added to restore the volume. The final solution was filtered by $0.22-\mu \mathrm{m}$ membrane and then determined by HPLC/ESI-MS/MS.

\subsection{HPLC/ESI-MS/MS Analysis}

2.4.1. Assay Method. HPLC/ESI-MS/MS analysis was performed on a TSQ Discovery triple-quadrupole mass spectrometer and a surveyor liquid chromatograph (Thermo Fisher Scientific, Waltham, MA, USA). Xcalibur 2.0.7 (Thermo Fisher Scientific) software was used to process the quantitative data obtained from calibration standards and samples.

2.4.2. HPLC Conditions. Methanol combined with $0.1 \%$ formic acid and $2 \mathrm{mmol} / \mathrm{L}$ ammonium acetate $(90: 10, \mathrm{v} / \mathrm{v})$ in LC-MS grade water were used as mobile phases. The injection volume was $5 \mu \mathrm{L}$. The flow rate was set $0.25 \mathrm{~mL} / \mathrm{min}$ and the column temperature at $30^{\circ} \mathrm{C}$, and the autosampler temperature was set at $5^{\circ} \mathrm{C}$. The analytical column was Sepax GP-C $_{18}, 150 \mathrm{~mm} \times 2.0 \mathrm{~mm}$ i.d. packed with $3 \mu \mathrm{m}$ particles (Sepax Technologies, USA).

2.4.3. MS/MS Conditions. The electrospray ionization- (ESI-) MS interface was operated in the positive ion mode with selected reaction monitoring (SRM). The ESI source conditions were shown below. Ion spray voltage was $4000 \mathrm{~V}$. Spray needle temperature was set at $350^{\circ} \mathrm{C}$. Sheath gas $\left(\mathrm{N}_{2}\right)$ was 35 (arbitrary) units, auxiliary gas $\left(\mathrm{N}_{2}\right)$ was $15 \mathrm{U}$, and collision gas (Ar) was 1.5 mTorr. Table 2 showed the MS/MS transitions 
TABLE 2: SRM conditions for target compounds.

\begin{tabular}{lccc}
\hline Compound & $\begin{array}{c}\text { Parent mass } \\
(\mathrm{m} / \mathrm{z})\end{array}$ & $\begin{array}{c}\text { Product mass } \\
(\mathrm{m} / \mathrm{z})\end{array}$ & $\begin{array}{c}\text { Collision } \\
\text { energy } \\
(\mathrm{V})\end{array}$ \\
\hline Carbendazim & 192 & $132^{*}$ & 27 \\
Carbendazim-D3 & 192 & 160 & 17 \\
\hline
\end{tabular}

${ }^{*}$ Quantitative ion.

RT: $0.00-5.00$ SM: $7 \mathrm{G}$
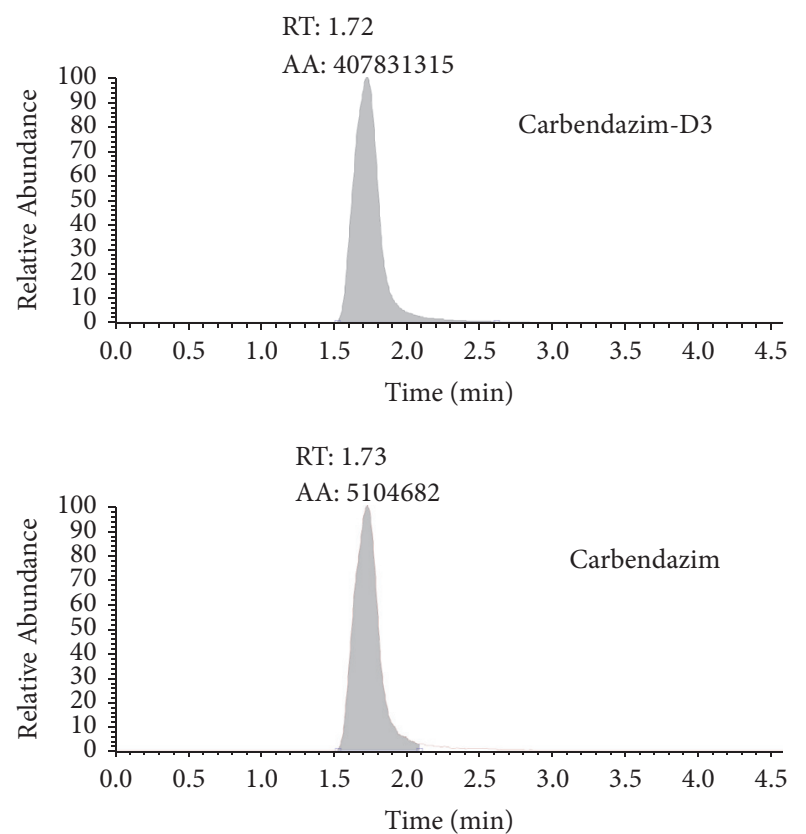

FIGURE 1: HPLC/ESI-MS/MS chromatograms of carbendazim and carbendazim-D3 in the standard solution.

selected for quantification and confirmation together with the optimized parameters for carbendazim and carbendazim-D3. The retention time of carbendazim and carbendazim-D3 was about 1.73 and $1.72 \mathrm{~min}$ in Figure 1.

2.5. Transfer Assessment and Mathematical Analysis for Curve Fitting. The transfer assessment of carbendazim residues from rape flowers to apicultural products was figured out by HPLC/ESI-MS/MS method. Mathematical curve fitting was identified by computer associated calculation on the basis of transfer assessment data.

\section{Results and Discussion}

3.1. Optimization of Sample Pretreatment. Pollen's pretreatment method developed from a fast and easy multiresidue method employing acetonitrile extraction/partitioning and dispersive solid-phase extraction for the determination of pesticide residues [19]. Honey's pretreatment method was improved from a confirmative method for sulfonamides, trimethoprim, and dapsone in honey by acidic hydrolysis and SPE [20]. Royal jelly's pretreatment method was improved from analysis of tetracycline residues in royal jelly by liquid chromatography-tandem mass spectrometry [21]. All pretreatments were modified and consisted of three steps: firstly, extraction with suitable solvents and, the second step, cleanup by dispersive solid-phase extraction technique. The third step comprised concentration, reconstitution, and filtration. The pretreatments were easy and operative.

3.2. Partial Validation of Analysis Method. Partial validation was carried out to evaluate the performances of the method for the quantitative analysis of carbendazim. To set up valid methods, performance characteristics, such as linear equation, linear range, accuracy, precision, limits of detection (LOD), and limits of quantification (LOQ), were determined. The methods were validated partially using the optimized conditions based on analysis time and resolution. The matrix could either enhance or suppress ionization of pesticides during the electrospray process. Therefore, blank samples of apicultural products (pesticide free) obtained from local markets were chosen as reference matrixes. In addition, concentration range of linear equation was chosen according to accuracy and sensitivity of SRM pattern during MS/MS analyses. Working standards at different concentrations were prepared by transferring $0.05,0.25,0.5,2.0$, 5.0 , and $25.0 \mathrm{~mL}$ of $2.0 \mathrm{mg} / \mathrm{L}$ intermediate working solution into separate $100 \mathrm{~mL}$ volumetric flasks and making up to volume with blank matrix extracts in methanol. Calibration curves were constructed using concentration $(\mathrm{mg} / \mathrm{L})$ versus the ratio (carbendazim area/carbendazim-D3 area) in the form of $y=a x+b$. The precision was the repeatability of signals calculated from 6 dependent injections with lowest concentration within the linear range $(C=0.001 \mathrm{mg} / \mathrm{L})$. The accuracy was evaluated by recovery yields with different adding concentrations at the beginning of the processing. LOD was determined as 3 times the signal to noise ratio of the quantitative ion transition by analysis of spiked sample containing carbendazim at low concentration levels with five replicate extractions. LOQ was defined as the lowest spiking level on acceptable recovery. Table 3 was the partial validation parameters for carbendazim added in different black samples. The results illustrated that the methods were reliable and sensitive to determine carbendazim in apicultural products.

3.3. Transfer Assessment. The transfer assessment of carbendazim residues from rape flowers to apicultural products was figured out by HPLC/ESI-MS/MS method.

Concentration of carbendazim in bee pollen was $99.2 \pm$ $20.5 \mathrm{mg} / \mathrm{kg} 1$ day after spraying, while $6.28 \pm 0.09 \mathrm{mg} / \mathrm{kg} 3$ days after spraying. That may be due to the rainy weather on 2nd day after spraying. The rain might wash away the pesticide covered on the surface of pollen. The data of 4 th day was higher than 3rd day which might be due to uneven application. The residues showed a downward trend and the decline of the speed was more and more slow after 4 days later. The residue on 18 th day was at $1.10 \pm 0.03 \mathrm{mg} / \mathrm{kg}$.

Concentration of carbendazim in bee honey was highest 6 days after spraying and then reduced. From 6 days to 18 days after spraying, the degradation rate of carbendazim became slower, while it suddenly turned out to be fast from 18 days to 
TABLE 3: Partial validation parameters for carbendazim added in different blank samples.

\begin{tabular}{lccc}
\hline Parameters & Pollen & Honey & Jelly \\
\hline Linear equation & $y=2.6182 x+0.0016$ & $y=0.8517 x+0.0042$ & $y=0.2220 x+0.0026$ \\
Linear range $(\mathrm{mg} / \mathrm{L})$ & $0.001-0.5$ & $0.001-0.1$ & $0.001-0.1$ \\
$R^{2}$ & 0.9999 & 0.9994 & 0.9998 \\
Repeatability of signals & 1.52 & 1.47 & 1.36 \\
(RSD, $\%, n=6$ dependent injections and $C=0.001 \mathrm{mg} / \mathrm{L})$ & & & 0.001 \\
LOD $(\mathrm{mg} / \mathrm{kg})$ & 0.001 & 0.01 & 0.01 \\
LOQ $(\mathrm{mg} / \mathrm{kg})$ & 0.01 & & $102 \pm 2.4$ \\
Recover $(\mathrm{mean} \pm \mathrm{RSD}), \%,(n=6)$ & & $95.7 \pm 8.4$ & $116 \pm 2.7$ \\
$0.01^{*}$ & $84.6 \pm 7.5$ & $101 \pm 6.1$ & $100 \pm 1.7$ \\
$0.2^{*}$ & $88.3 \pm 4.2$ & $110 \pm 8.7$ & \\
$1.0^{*}$ & $90.2 \pm 5.3$ & & \\
\hline
\end{tabular}

* (Added level, $\mathrm{mg} / \mathrm{kg}$ ).

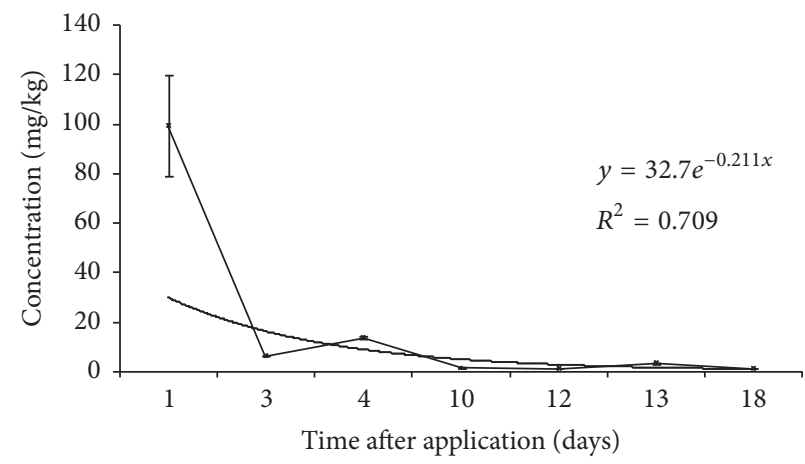

(a)

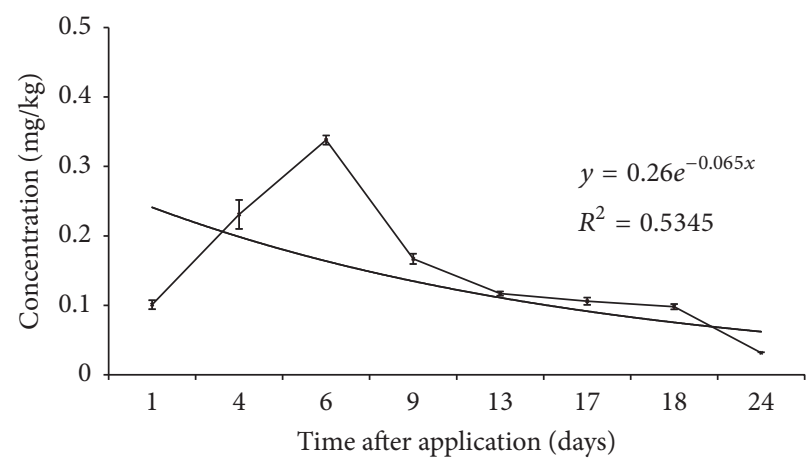

(b)

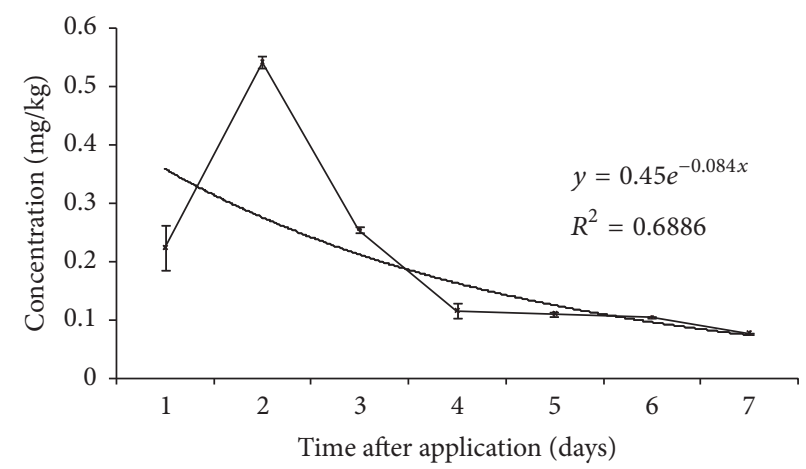

(c)

FIGURE 2: The concentration change of carbendazim in apicultural products established by mathematical analysis for curve fitting (a) pollen; (b) honey; (c) jelly.

24 days after spraying. The residue on 24 th day was at $0.032 \pm$ $0.001 \mathrm{mg} / \mathrm{kg}$.

Concentration of carbendazim in bee jelly was highest 6 days after spraying and then reduced. The degradation rate of carbendazim was very slow after 12 days. The residue on the 22nd day was at $0.077 \pm 0.002 \mathrm{mg} / \mathrm{kg}$.

3.4. Mathematical Analysis for Curve Fitting. Mathematical analysis for curve fitting was carried out on the basis of transfer assessment of carbendazim residues from rape flowers to apicultural products.
The fitting curves were obtained by professional function drawing software including Excel (2013 version) and Origin 9.1. Firstly, $P$ value was obtained from Origin 9.1. The curve was fit if $P<0.05$ [22]. Pesticide residues of corresponding time could be found from the drawn fitting curve [23]. Calibration curves were constructed using time after spraying pesticide application (days) versus carbendazim residues $(\mathrm{mg} / \mathrm{kg})$ in the form of exponential function. By mathematical curve fitting, the exponential function simulation of carbendazim residues in pollen was $y=32.7 e^{-0.211 x}\left(R^{2}=\right.$ 0.709 ) as shown in Figure 2(a). $P$ value was $4.11 * 10^{-5}<0.05$; thus the reliability of curve fitting was confirmed. The results 
obtained from curve fitting showed that the degradation halflife of carbendazim in pollen was about 1.98 days.

In this same way, the exponential function simulation of carbendazim residues in honey was $y=0.26 e^{-0.065 x}\left(R^{2}=\right.$ $0.5345)$ as shown in Figure $2(\mathrm{~b}) . P$ value was $0.0101<0.05$. According to recommended dose of carbendazim, the results obtained from curve fitting showed that the degradation halflife of carbendazim in honey was about 25.2 days.

By the same method, the exponential function simulation of carbendazim residues in royal jelly was $y=0.45 e^{-0.084 x}$ $\left(R^{2}=0.6886\right)$ as shown in Figure 2(c). $P$ value was $0.0253<$ 0.05 . The results obtained from curve fitting showed that the degradation half-life of carbendazim in jelly was about 16.7 days.

\section{Conclusion}

The results of this study indicate a practical approach to study pesticide residues from rape flowers to apicultural products by HPLC/ESI-MS/MS method. The method is validated reliable and sensitive to determine carbendazim in apicultural products. Transfer assessment and mathematical curve fitting of carbendazim residues from rape flowers to apicultural products show that the residues of carbendazim are reduced with spraying time. The gap of carbendazim residues between pollen and honey is decreased with time.

The carbendazim residues in pollen are 10 times higher than that in honey and jelly. The study can help farmers to keep safe intervals of corresponding fungicides. The study can provide data support for the analysis of the residue limits and risk assessment of carbendazim in apicultural products and to improve security level of apicultural products.

\section{Competing Interests}

The authors declare that they have no competing interests.

\section{Acknowledgments}

The authors acknowledge financial support from the National Natural Science Foundation of China (21207118), the Project of Science and Technology Plan of Zhejiang Province, China (2014C37103), and the Natural Science Foundation of Zhejiang Province, China (LY15B070002).

\section{References}

[1] J. Le Faouder, E. Bichon, P. Brunschwig, R. Landelle, F. Andre, and B. Le Bizec, "Transfer assessment of fipronil residues from feed to cow milk," Talanta, vol. 73, no. 4, pp. 710-717, 2007.

[2] R. Li, W. Wei, L. He et al., "Chlorpyrifos residual behaviors in field crops and transfers during duck pellet feed processing," Journal of Agricultural and Food Chemistry, vol. 62, no. 42, pp. 10215-10221, 2014.

[3] R. Li, X. F. Ji, L. He et al., "Evaluation of chlorpyrifos transferred from contaminated feed to duck commodities and dietary risks to Chinese consumers," Journal of Agricultural and Food Chemistry, vol. 63, no. 21, pp. 5296-5304, 2015.
[4] P. Premratanachai and C. Chanchao, "Review of the anticancer activities of bee products," Asian Pacific Journal of Tropical Biomedicine, vol. 4, no. 5, pp. 337-344, 2014.

[5] M. F. Zayats, S. M. Leschev, and M. A. Zayats, "An improved extraction method of rapeseed oil sample preparation for the subsequent determination in it of azole class fungicides by gas chromatography," Analytical Chemistry Research, vol. 3, pp. 3745, 2015.

[6] Y.-L. Di, Z.-Q. Zhu, X.-M. Lu, and F.-X. Zhu, "Baseline sensitivity and efficacy of trifloxystrobin against Sclerotinia sclerotiorum," Crop Protection, vol. 87, pp. 31-36, 2016.

[7] A. David, C. Botías, A. Abdul-Sada et al., "Widespread contamination of wildflower and bee-collected pollen with complex mixtures of neonicotinoids and fungicides commonly applied to crops," Environment International, vol. 88, pp. 169-178, 2016.

[8] G.-X. Wei, J.-K. Huang, and J. Yang, "Honey safety standards and its impacts on China's honey export," Journal of Integrative Agriculture, vol. 11, no. 4, pp. 684-693, 2012.

[9] T. Kiljanek, A. Niewiadowska, S. Semeniuk, M. Gaweł, M. Borzecka, and A. Posyniak, "Multi-residue method for the determination of pesticides and pesticide metabolites in honeybees by liquid and gas chromatography coupled with tandem mass spectrometry-Honeybee poisoning incidents," Journal of Chromatography A, vol. 1435, pp. 100-114, 2015.

[10] J. Wang, W. Cheung, and D. Leung, "Determination of pesticide residue transfer rates (percent) from dried tea leaves to brewed tea," Journal of Agricultural and Food Chemistry, vol. 62, no. 4, pp. 966-983, 2014.

[11] N. Manikandan, S. Seenivasan, M. N. K. Ganapathy, N. N. Muraleedharan, and R. Selvasundaram, "Leaching of residues of certain pesticides from black tea to brew," Food Chemistry, vol. 113, no. 2, pp. 522-525, 2009.

[12] A. Rortais, G. Arnold, M.-P. Halm, and F. Touffet-Briens, "Modes of honeybees exposure to systemic insecticides: estimated amounts of contaminated pollen and nectar consumed by different categories of bees," Apidologie, vol. 36, no. 1, pp. 7183, 2005.

[13] J. Weick and R. S. Thorn, "Effects of acute sublethal exposure to coumaphos or diazinon on acquisition and discrimination of odor stimuli in the honey bee (Hymenoptera: Apidae)," Journal of Economic Entomology, vol. 95, no. 2, pp. 227-236, 2002.

[14] M. I. S. Škerl, Š. Velikonja Bolta, H. Baša Česnik, and A. Gregorc, "Residues of pesticides in honeybee (apis mellifera carnica) bee bread and in pollen loads from treated apple orchards," Bulletin of Environmental Contamination and Toxicology, vol. 83, no. 3, pp. 374-377, 2009.

[15] Ż. Bargańska, M. Ślebioda, and J. Namieśnik, "Pesticide residues levels in honey from apiaries located of Northern Poland," Food Control, vol. 31, no. 1, pp. 196-201, 2013.

[16] P. Calatayud-Vernich, F. Calatayud, E. Simó, M. M. SuarezVarela, and Y. Picó, "Influence of pesticide use in fruit orchards during blooming on honeybee mortality in 4 experimental apiaries," Science of the Total Environment, vol. 541, pp. 33-41, 2016.

[17] G. Codling, Y. A. Naggar, J. P. Giesy, and A. J. Robertson, "Concentrations of neonicotinoid insecticides in honey, pollen and honey bees (Apis mellifera L.) in central Saskatchewan, Canada," Chemosphere, vol. 144, pp. 2321-2328, 2016.

[18] M. Lombardo-Agüí, A. M. García-Campaña, L. Gámiz-Gracia, and C. Cruces-Blanco, "Determination of quinolones of veterinary use in bee products by ultra-high performance liquid 
chromatography-tandem mass spectrometry using a QuEChERS extraction procedure," Talanta, vol. 93, pp. 193-199, 2012.

[19] L. Wiest, A. Buleté, B. Giroud et al., "Multi-residue analysis of 80 environmental contaminants in honeys, honeybees and pollens by one extraction procedure followed by liquid and gas chromatography coupled with mass spectrometric detection," Journal of Chromatography A, vol. 1218, no. 34, pp. 5743-5756, 2011.

[20] A. Economou, O. Petraki, D. Tsipi, and E. Botitsi, "Determination of a liquid chromatography-tandem mass spectrometry method for the determination of sulfonamides, trimethoprim and dapsone in honey and validation according to Commission Decision 2002/657/EC for banned compounds," Talanta, vol. 97, pp. 32-41, 2012.

[21] J.-Z. Xu, T. Ding, B. Wu et al., "Analysis of tetracycline residues in royal jelly by liquid chromatography-tandem mass spectrometry," Journal of Chromatography B, vol. 868, no. 1-2, pp. 42-48, 2008.

[22] L. Chen, Y. Li, T. Wang, Y. Jiang, K. Li, and Y. Yu, "Microencapsulated chlorpyrifos: degradation in soil and influence on soil microbial community structures," Journal of Environmental Sciences (China), vol. 26, no. 11, pp. 2322-2330, 2014.

[23] P. E. Athanasopoulos, C. Pappas, N. V. Kyriakidis, and A. Thanos, "Degradation of methamidophos on soultanina grapes on the vines and during refrigerated storage," Food Chemistry, vol. 91, no. 2, pp. 235-240, 2005. 

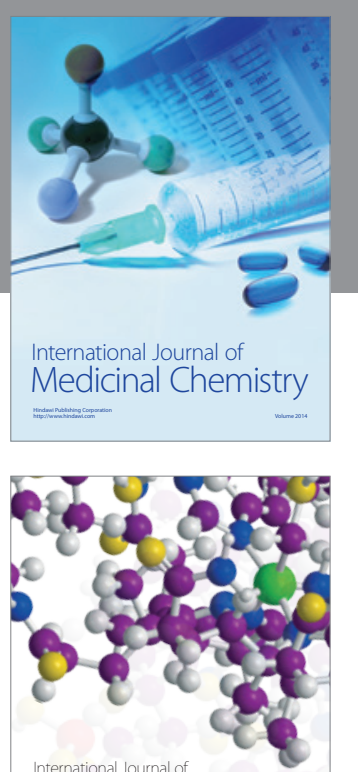

Carbohydrate Chemistry

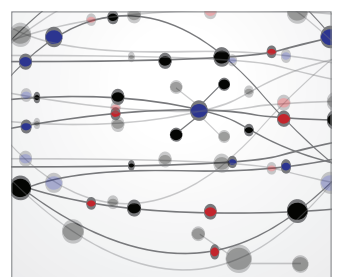

The Scientific World Journal
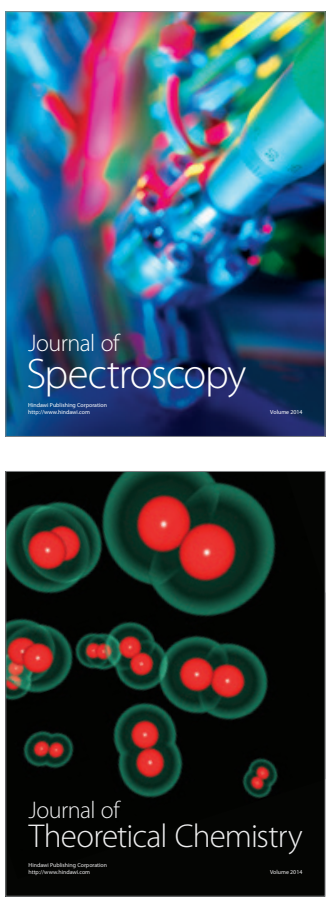
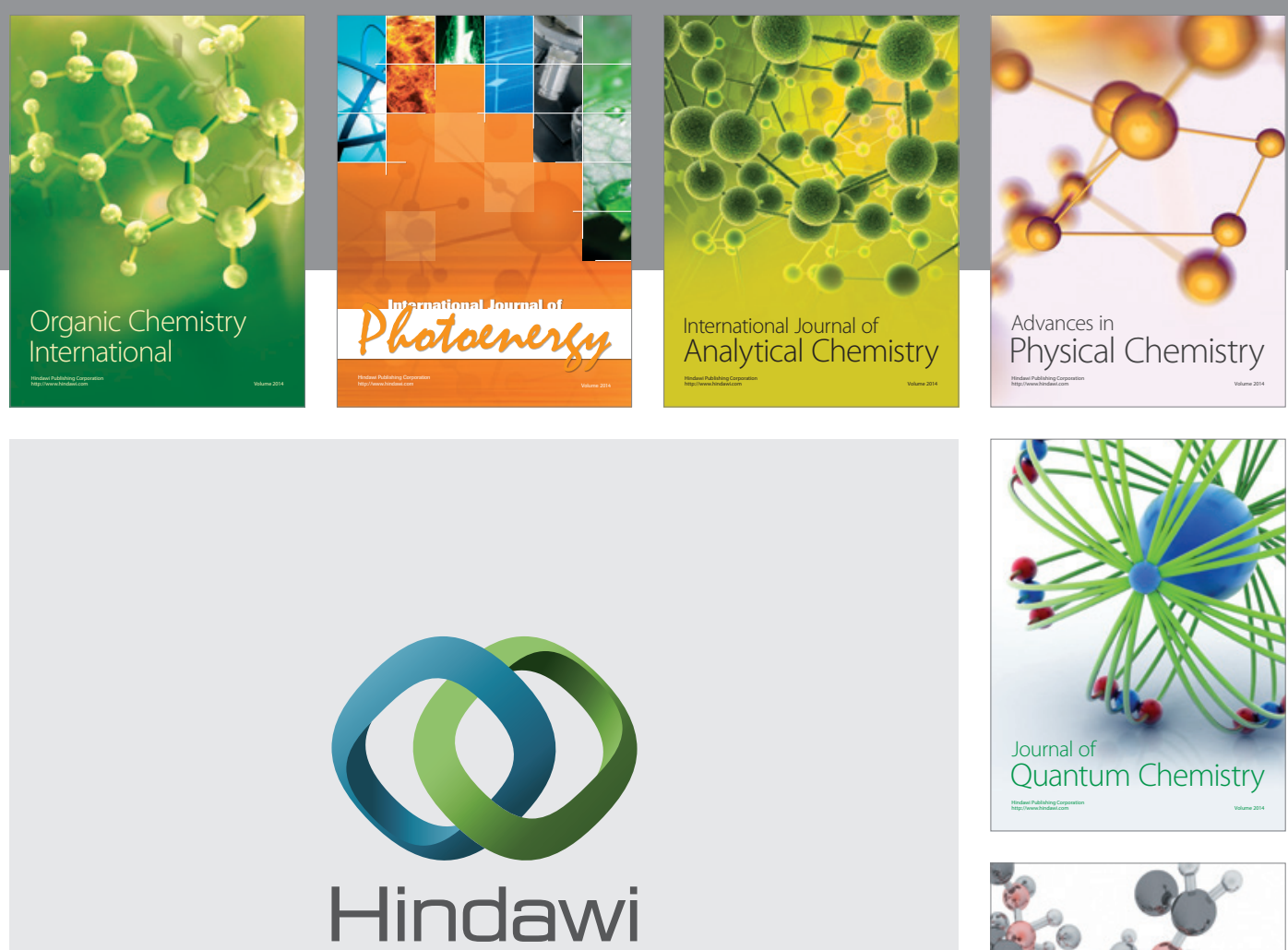

Submit your manuscripts at

https://www.hindawi.com

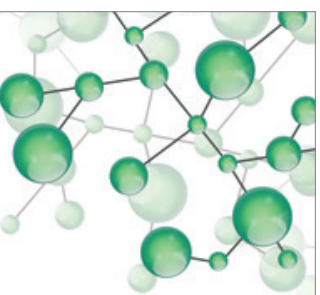

International Journal of

Inorganic Chemistry
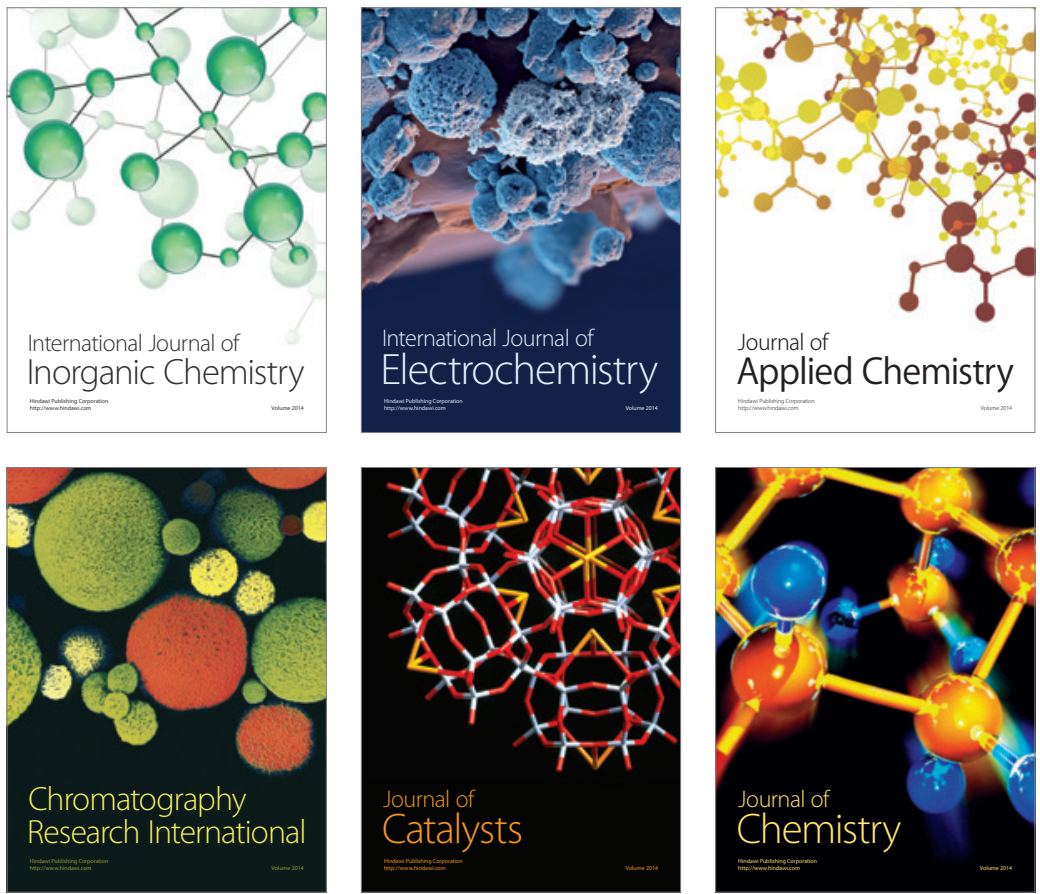

Journal of

Applied Chemistry
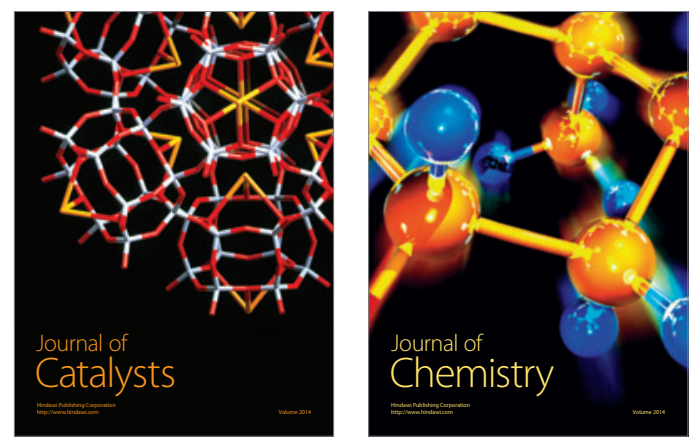
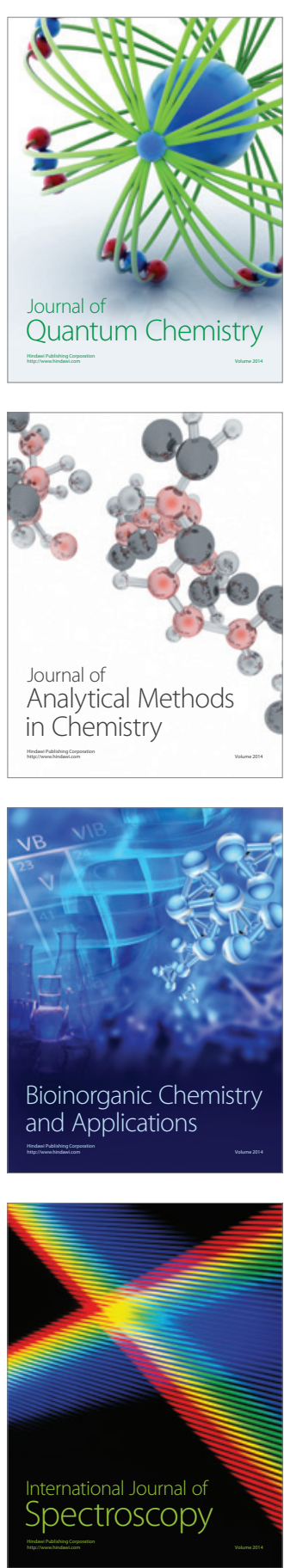